\title{
Djinnati syndrome as the first manifestation of temporal lobe epilepsy: A case report
}

\author{
Mohsen Khosravi
}

Department of Psychiatry and Clinical Psychology, Zahedan University of Medical Sciences, Zahedan, Iran

This article is distributed under the terms of the Creative Commons Attribution Noncommercial License (CC BY-NC 4.0) which permits any noncommercial use, distribution, and reproduction in any medium, provided the original author(s) and source are credited.

\begin{abstract}
Culture-bound syndromes are a group of abnormal behavior patterns occurring only in definite cultural groups. As a form of culture-bound syndromes, possession trance is known as the "replacement of personal identity customary sense by a new identity." Djinnati syndrome is a possession state restricted to specific areas of Iranian and Pakistani Baluchestan. Preceding studies suggested that complex behavioral manifestations of temporal lobe epilepsy (TLE) were likely to contain dissociative states symptoms. Nonetheless, people in numerous developing countries hold a belief that Jinn possession causes epilepsy even in quite well-educated people. The aims of the present report are to describe a patient who presented Djinnati syndrome as the very first manifestation of TLE and address the feasible detrimental impacts of cultural misconceptions on diagnosing and treating epileptic seizures.
\end{abstract}

Key Words: Culture-bound syndromes; Djinnati syndrome; possession trance; seizure; temporal lobe epilepsy.

Eur J Transl Myol 31 (4): 10052, 2021 doi: 10.4081/ejtm.2021.10052

Culture-bound syndromes are defined by psychiatric and somatic symptoms assumed as illness behavior in a specific socio-cultural context. In the anthropological and psychiatric literature, culture-bound syndromes have been categorized as two forms of dissociative phenomena, including possession trance and dissociative trance. Possession trance involves the "replacement of customary sense of personal identity by a new identity." However, within dissociative trance, the loss of customary identity does not relate to the appearance of alternate identities. ${ }^{1}$ Djinnati (as a culture-bound syndrome firstly introduced by Bakhshani and Kianpoor) is a possession state known in certain regions of Iranian and Pakistani Baluchestan. During attacks of Djinnati syndrome, the patient develops impaired consciousness, amnesia, agitation, incoherent speech, hallucination, aimless behavior, and adopts the identity of the Djinnan invisible creature of God believed by Muslims to live in our world and be able to impact our lives in various ways. ${ }^{2}$ Previous studies stated that complex behavioral manifestations of temporal lobe epilepsy (TLE) might include symptoms of dissociative states. ${ }^{3}$ However, in many developing countries, people believe that Jinn possession triggers epilepsy even among relatively welleducated people. ${ }^{4}$ The present report aims at describing a patient who showed Djinnati syndrome as the first manifestation of TLE, as well as highlighting the possible detrimental effect of cultural misconceptions on the proper diagnosis and treatment of epileptic seizures.

\section{Materials and Methods}

\section{Case Report}

A young female from the Baluch ethnic group referred to Baharan psychiatric hospital, Zahedan, Iran, complaining of Djinnati syndrome attacks for the last three years. After establishing trust and rapport, the patient was assessed using basic principles of evaluation, including interviewing and mental status examination. For further information, a supplementary interview was conducted with the family members, friends, and previous physician of the patient. In addition, a physical examination was examined to determine if these symptoms were due to a neurological disorder. Psychological tests (e.g., Beck's Depression Inventory-II and Dissociative Experiences Scale), clinical and paraclinical tests (including electroencephalography, thyroid-stimulating hormone, and Vitamin B12), and imaging assessment (i.e., Magnetic Resonance Imaging of brain) were also performed. Clinical data were collected following ethical principles reported in the Declaration of Helsinki. ${ }^{5}$

\section{Results}

The patient was a 26-year old married Iranian female referred to Baharan psychiatric hospital, Zahedan, Iran, with a chief complaint of Djinnati syndrome attacks for the last three years. During these attacks, she began to speak in masculine texture/tone about harassing the patient and killing her husband following unusual head 


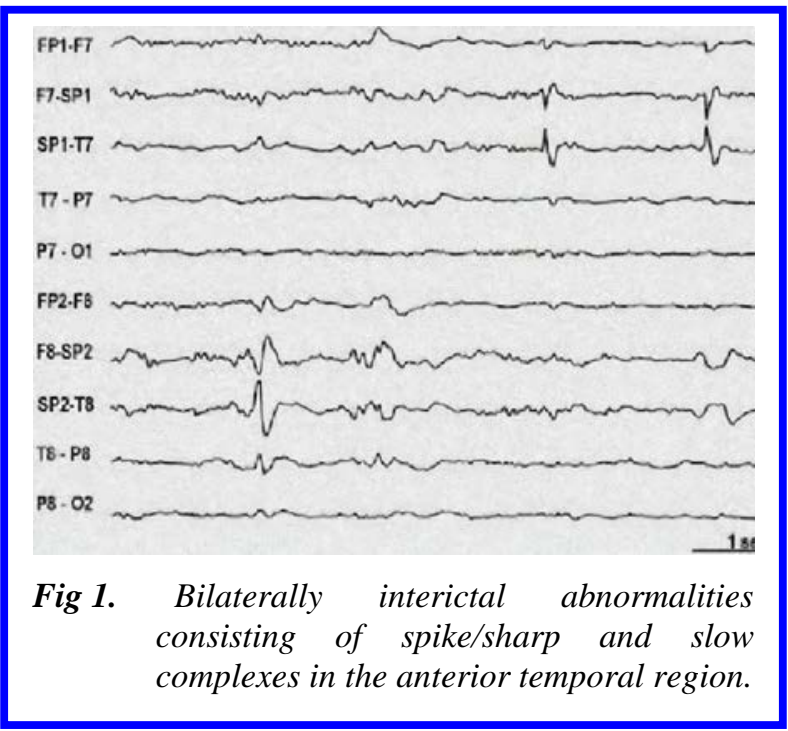

twisting and repetitive blinking. Such attacks occurred 2 to 3 times a day (almost every day) and lasted for 3 to 5 minutes. In the intervals between the attacks, the patient claimed to be unaware of her utterances and movements and identified the cause as a demon. However, there were no findings in favor of somatoform, substance use, and stress-related disorders. Furthermore, no significant points were observed in the personal history (trauma in any form and abuse in particular), family history, and physical examination of the patient. The mental status examination and physical assessments were unremarkable except for preoccupation with exorcism, poor attention and concentration, anxious affect, and immediate memory impairment. On Beck's Depression Inventory-II, her score was 51, indicating severe depression. The Dissociative Experiences Scale also showed a score of 65, i.e., a severe level of dissociation. Electroencephalography was performed, which revealed bilaterally interictal abnormalities consisting of spike/sharp and slow complexes in the anterior temporal region (F7/F8 and T7/T8 electrodes; see Figure 1). Coronal slice on brain Magnetic Resonance Imaging showed bilateral hippocampal atrophy. Besides, the markedly increased T2-weighted signal intensity in the hippocampus was observed on fluid-attenuated inversion recovery (Figure 2). Patient laboratory tests including thyroid-stimulating hormone and Vitamin B12 were included in the normal range. Although she had been treated by local healers (mullah) several times during these three years, no clinical response was received. She was eventually diagnosed with TLE and major depressive disorder by psychiatrist and treated with Sertraline 50mg/day and Levetiracetam 500mg three times a day. On these doses, she responded well with the reduction in the number and intensity of possession attacks and improvement in mood and sociooccupational functions within one-half months of treatment. Finally, sertraline was gradually tapered after one year of treatment and currently she is only on

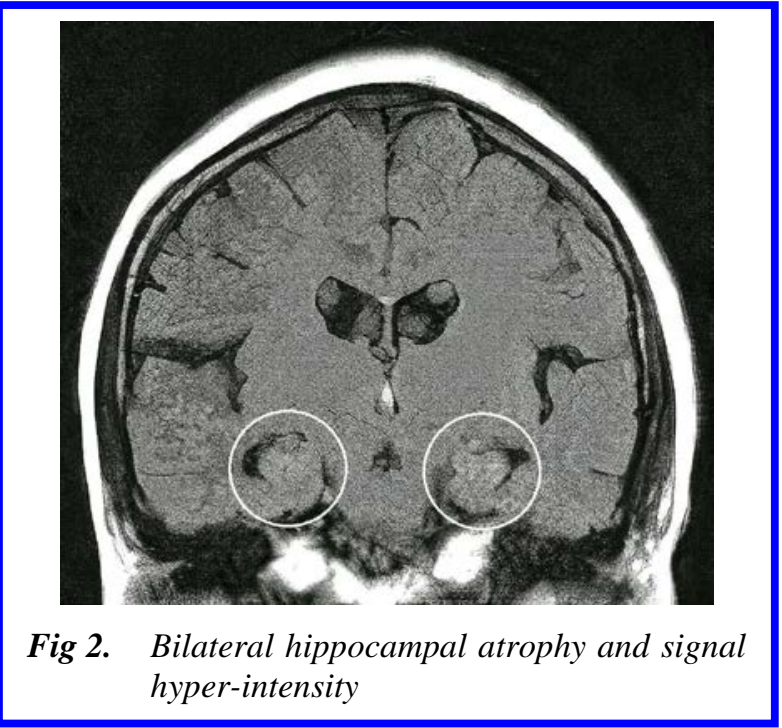

Levetiracetam 500mg three times a day and free of symptoms.

\section{Discussion}

This report has two practical implications. At first, although the Diagnostic and Statistical Manual of Mental Disorders, Fifth Edition (DSM-5) has identified possession trance as one of the dissociative disorders, this case proves that epileptic seizures can have a presentation similar to the so-called culture-bound syndrome. ${ }^{6-10}$ Therefore, clinicians should consider neurological abnormalities (e.g. TLE) for every case involving possession trance. Second, when treating patients with epilepsy in developing countries, clinicians must consider application of religious and cultural beliefs to unexplainable incidences. ${ }^{8,11,12}$ In all, the patient's system of beliefs and cultural background can permit simple religious concepts to explain a range of life circumstances, including medical conditions, and hamper clinical management of TLE by delaying or avoiding proper diagnosis and treatment. ${ }^{4}$ The present finding underscores the need to improve public epilepsy education at all levels and communication with faith healers.

\section{List of acronyms}

DSM-5 - Diagnostic and Statistical Manual of Mental Disorders, Fifth Edition

TLE - Temporal lobe epilepsy

\section{Authors contributions}

MK fully wrote the article and approved the final version of the manuscript.

\section{Acknowledgments}

The author would like to thank the patient, who contributed in conducting the present study

\section{Funding}

The author received no specific funding for this work. 


\section{Conflict of Interest}

The author declares no financial, personal, or other conflicts of interes.

\section{Ethical Publication Statement}

We confirm that we have read the Journal's position on issues involved in ethical publication and affirm that this report is consistent with those guidelines.

\section{Corresponding Author}

Mohsen Khosravi, MD, Department of Psychiatry and Clinical Psychology, Baharan Psychiatric Hospital, Zahedan University of Medical Sciences, Postal Code: 9813913777, Zahedan, Iran.

Tel: +98-5433522636, Fax: +98-5433518352.

ORCID ID: 0000-0003-2970-6309

Email: dr_khosravi2016@yahoo.com

\section{References}

1. Igreja V, Dias-Lambranca B, Hershey DA, Racin L, Richters A, Reis R. The epidemiology of spirit possession in the aftermath of mass political violence in Mozambique. Soc Sci Med. 2010 Aug;71(3):592-9. doi: 10.1016/j.socscimed.2010.04 024. Epub 2010 May 12.

2. Hosseinbor N, Bakhshani NM. Djinnati syndrome in baluchestan: the role of traumatic and abuse experiences on individual vulnerability. Int J High Risk Behav Addict. 2014 Nov;3(4):e23610. doi: 10.5812/ijhrba.23610.

3. Medford N. Dissociative symptoms and epilepsy. Epilepsy Behav. 2014 Jan;30:10-3. doi: 10.1016/j.yebeh.2013.09.038. Epub 2013 Nov 4.

4. Obeid T, Abulaban A, Al-Ghatani F, Al-Malki AR, Al-Ghamdi A. Possession by 'Jinn' as a cause of epilepsy (Saraa): a study from Saudi Arabia. Seizure. 2012 May;21(4):245-9. doi: 10.1016/j.seizure. 2012.01.001. Epub 2012 Feb 5.
5. Goodyear MD, Krleza-Jeric K, Lemmens T. The Declaration of Helsinki. BMJ. 2007 Sep;335(7621):624-5. doi: 10.1136/bmj.39339. 610000.BE.

6. Mesulam MM. Dissociative states with abnormal temporal lobe EEG. Multiple personality and the illusion of possession. Arch Neurol. 1981 Mar;38(3):176-81.

doi: 10.1001/archneur.1981.00510030070010.

7. Carrazana E, DeToledo J, Tatum W, Rivas-Vasquez R, Rey G, Wheeler S. Epilepsy and religious experiences: Voodoo possession. Epilepsia. 1999 Feb;40(2):239-41. doi: 10.1111/j.15281157.1999.tb02081.x.

8. Cavanna AE, Cavanna S, Cavanna A. Epileptic seizures and spirit possession in Haitian culture: report of four cases and review of the literature. Epilepsy Behav. 2010 Sep;19(1):89-91. doi: 10.1016/j.yebeh.2010.07.002. Epub 2010 Aug 17.

9. Hecker T, Barnewitz E, Stenmark H, Iversen V. Pathological spirit possession as a cultural interpretation of trauma-related symptoms. Psychol Trauma. 2016 Jul;8(4):468-76. doi: 10.1037/tra0000117. Epub 2016 Mar 31.

10. Bhavsar V, Ventriglio A, Bhugra D. Dissociative trance and spirit possession: Challenges for cultures in transition. Psychiatry Clin Neurosci. 2016 Dec;70(12):551-9. doi: 10.1111/pcn.12425. Epub 2016 Sep 18.

11. Bone I, Dein S. Religion, spirituality, and epilepsy. Epilepsy Behav. 2021 Jul;122:108219. doi: 10. 1016/j.yebeh.2021.108219. Online ahead of print.

12. Mesraoua B, Kissani N, Deleu D, Elsheikh L, Ali M, Melikyan G, Al Hail H, Wiebe S, Asadi-Pooya AA. Complementary and alternative medicine (CAM) for epilepsy treatment in the Middle East and North Africa (MENA) region. Epilepsy Res. 2021 Feb;170:106538. doi: 10.1016/j.eplepsyres.2020. 106538. Epub 2021 Jan 11.

Submission: August 21, 2021

Revision submitted: September 1, 2021 Accepted for publication: September 1, 2021 